\title{
The use of mobile applications by public transport commuters in Gauteng, South Africa
}

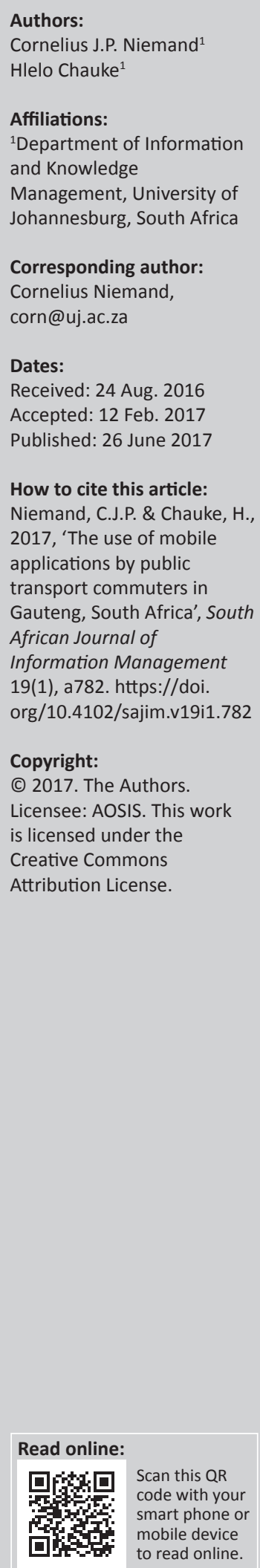

Background: Information and Communication Technology (ICT) has brought about a 'singularity' - that is 'an event which changes things so fundamentally that there is absolutely no going back'. The aforesaid change may be attributed to the way that the modern consumer thinks, communicates and interacts with the environment. Because businesses need to adapt and offer new, innovative ways of products and service delivery, early technology adopters are more likely to experience favourable business outcomes, including increased revenue potential and a better market position in comparison to competitors.

Objectives: The transport industry may be regarded as early adopters of new technology. Thus, the objective of this study is to determine the perceived use and usefulness of mobile applications used within the public transport industry of South Africa.

Method: This study adopted a positivist stance with a deductive research approach utilising the technology acceptance model theory as a departure point for the study. A mixed method research design was selected for this exploratory study, utilising a survey strategy comprising both closed and open-ended questions as a snapshot of the perceived usefulness of a mobile application within the South African public transport domain. A convenience sample of a hundred Gautrain commuters was selected.

Main findings: Based on descriptive statistics, the main findings of this study indicate a positive relationship between the perceived ease of use and usefulness of the Gautrain Buddy application in the dissemination of Gautrain-specific information. Some of the results of the study have also been presented at an international conference [for the conference details, please refer to the reference list Niemand and Chauke (2016)].

Conclusion: The sample of commuters forming part of the study indicates that mobile applications can be useful in the dissemination of public transport information in Gauteng, South Africa.

\section{Introduction}

The onset and rapid diffusion of Information and Communication Technology (ICT) in the last decade of the 20th century has brought about a 'singularity' - that is 'an event which changes things so fundamentally that there is absolutely no going back' within the way that the modern consumer thinks, communicates and interacts with the environment (Prensky 2001). Nicholas et al. (2003:23) concurs and adds that it is '...not just the number of people using the system that changed so dramatically, the types of people using the system changed dramatically too...'. According to Spink (2004:336), 'the growing complexity of everyday life and work environments often requires people to engage in multitasking behaviours'.

Taking the aforesaid statements into consideration, business has had to adapt to the new way consumers interact and engage with information and the brand itself. One of the most significant developments within the business environment during the last century is the ability of organisations to deliver products and or services via technological means to the consumers thereof. According to Wentzel, Diatha and Yadavalli (2013) 'computers, mobile telephones, the Internet and self-service devices are examples of technology platforms that have enabled services to be offered in new and innovative ways'. Considering that businesses need to adapt and offer new innovative ways of products and service delivery, Cusanelli (2014) postulates that early technology adopters are more likely to experience favourable business outcomes, including increased revenue potential and a better market position in 
comparison to competitors. The aforementioned statement is supported by a study (The Digital Dividend-First Mover Advantage) completed by the Harvard Business Review Analytic Services (n.d.).

Challenger (2015) is of the opinion that the transport industry may be regarded as early adopters of new technology. Robinson (2015) concurs and adds that mobile technology is not new to the transportation world. The author furthermore points to various examples including Qualcomm's OmniTracs $^{\mathrm{TM}}$ in 1988 and UPS' roll-out of the Delivery Information Acquisition Device (DIAD) 4 years later of pioneering companies investing in mobile technology as a means to drive efficiencies and create competitive advantage. Based on the fact that the transport industry may be regarded as early adopters of technology, the main research question may be defined as:

Does the use of mobile applications assist in information dissemination within the public transport industry in Gauteng, South Africa?

The main research objectives of the study are to determine:

- What is the perceived usefulness of mobile applications in the dissemination of information in the public transport industry?

- What is the perceived ease of use of mobile application in the dissemination of information in the public transport industry?

\section{Theoretical framing}

Theoretical frameworks provide a base position from which researchers engage with and view knowledge within a particular field of study. Depending on the methodological orientation of the researcher, the same phenomenon may be viewed from varying theoretical frameworks. The aforesaid frameworks may be defined in terms of the scholarly reality within which the researcher endeavours to answer a research problem and or partly relating to the framework that the researcher consciously pursues to describe and understand the phenomenon. Considering the importance of the theoretical framework, Agherdien (2007:17) argues that frameworks may be regarded as 'epistemological devices that account for the knowledge that is produced in a study'. The objective of a theory is to guide the study and research process in three unique ways. Agherdien (2007:20) is of the opinion that a theory may pertain to and guide the philosophy of the science and the way the research is designed, the way a phenomenon is viewed within a specific academic or disciplinary stance or the way it facilitates critical review of previous research and how it relates to a specific study. In order to justify the importance of the three guiding functions of a theory, it is necessary to define the concept of a theory. Pettigrew and McKechnie (2001:62) are of the opinion that within the modern day research environment, having a theory is an indication of research importance and research respectability. The dynamic nature of research impact on how a theory will be defined, for what is acceptable as the correct theory today, may be replaced by an updated, more descriptive theory tomorrow. The aforementioned statement is justified if the definition as postulated by Flick (1998:43) in Agherdien (2007) who states that a theory may be seen as a 'versions of the world' that are said to be revised, evaluated, constructed and reconstructed on a continuous basis, is taken into account. Gorard (2004) concurs with Flick (1998:43) and postulates that a theory is 'a tentative explanation, used for as long as it usefully explains or predicts real-world events'. Pettigrew and McKechnie (2001:62) are of the opinion that a theory may be represented in a written and or graphical format.

The theoretical framing or theory used in this study is the 'technology acceptance model' (TAM). The TAM attempts to explain the phenomenon of the users' acceptance of a specific system and the subsequent use thereof. It should be noted that the TAM has been widely applied, validated and cited within the Information Management (IM) and ICT fields. The importance of aforesaid is evident from the statement by Lee, Kozar and Larsen (2003:764) indicating that 'TAM studies occupy $10 \%$ of total (leading information systems [IS] journals) publications'.

\section{Technology acceptance model}

A number of different theories have been postulated in an attempt to explain the adoption of technology by its users. According to Wentzel et al. (2013), the first attempt at explaining how users go about adopting technology was the 'Theory of Reasoned Action'. It should be noted that the Theory of Reasoned Action describes the behaviour of a user of technology from a social psychological point of view, that is, the theory attempts to identify the causes of conscious intended behaviours and maintains that these behaviours are a function of the user's attitude towards the intended behaviour. The Theory of Reasoned Action does have a limitation in its inability to explain behaviour in which people have limited control. The Theory of Reasoned Action was therefore extended to the Theory of Planned Behaviour that accounts for situations or conditions where users do not have full control over the situation.

Wentzel et al. (2013) is of the opinion that the first theory that focuses specifically on the adoption of technology by its users was introduced by Fred Davis in the late 1980s. According to Lala (2014), Davis postulated that the TAM aims 'to provide an explanation of the determinants of computer acceptance that are generally able to explain the behaviour of users of a wide range of computing technology'. Lala (2014) furthermore states that Davis postulated that the use of a system can be explained or predicted by users' motivation, which in turn, is directly influenced by an external stimulus in the form of the actual system features and capabilities. The aforementioned interaction may be graphically summarised by means of Figure 1 .

Taking the aforesaid into consideration, the TAM as postulated by Davis may be regarded as a theoretical basis for specifying the casual relationship between the two main sets of constructs 


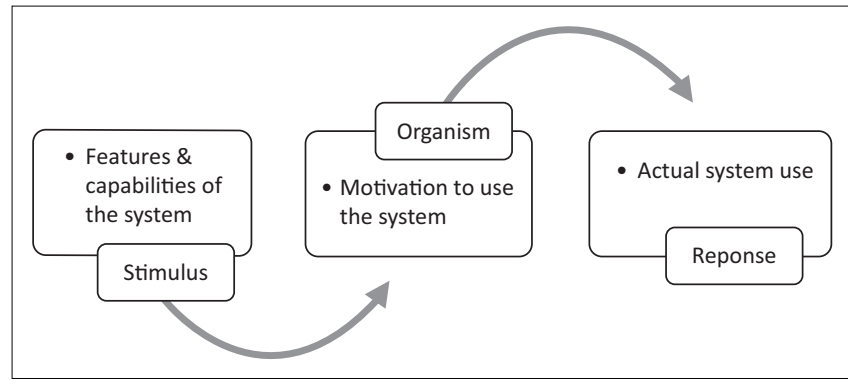

Source: Adapted from Lala, G., 2014, The emergence and development of the technology acceptance model (TAM), viewed 28 January 2015, from http://0-web.b.ebscohost.com. ujlink.uj.ac.za/

FIGURE 1: Davis' conceptual model for technology acceptance.

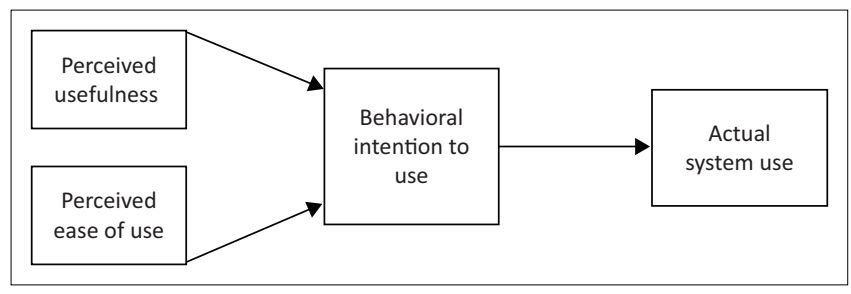

Source: Adapted from: Davis, F.D., Bagozzi, R.P. \& Warshaw, P.R., 1989, 'User acceptance of computer technology: A comparison of two theoretical models', Management Science 35(8), 982-1003. https://doi.org/10.1287/mnsc.35.8.982

FIGURE 2: Technology acceptance model.

identified, that is, perceived usefulness and perceived use of the system. Fădor (2014:61) states that Davis defined perceived usefulness as 'the degree to which a person believes that using a particular system would enhance his performance at work' and perceived ease of use being defined as 'the degree to which a person believes that using a particular system would be free of effort'. Thus, the model states that the perceived usefulness and the perceived ease of use will predict the attitude towards the system. Fădor (2014:61) defines the attitude towards the system as 'the user's willingness to use its own system'. Furthermore the model dictates that the users' attitude and perceived usefulness will influence the behavioural intention of the users to use the system, where the actual use of the system is dictated by the behavioural intention of the users to use the system (Figure 2).

According to Radomir and Nistor (2013) over the last couple of years, several adjustments have been made to the original TAM. These adjustments include but are not limited to:

- researchers removing or adding new relationships between the variables in the model

- some researchers remove behavioural intention and actual usage behaviour from the model

- differences have also been noticed relating to external variable identification and incorporation that may influence individuals' beliefs and thus their specific behaviours

- other researchers rename behavioural intention to continuance intention when the study is conducted among users of a particular information system.

For the purpose of this study, the fundamental or initial TAM will be used to determine the perceived use and usefulness of mobile application in the public transport industry in Gauteng, South Africa.

\section{South African transport industry}

According to a PwC (n.d.) report the transport sector is a key contributor to South Africa's competitiveness in global markets'. The report suggests that the air and rail networks within South Africa may be regarded as the largest on the African continent. Ports and ports efficiencies has improved because of high levels of investment within this sector of the transport industry. But, because of a lack of intermodal transport infrastructure the South African economy overrelies on road transport to mitigate the legacy infrastructure issues created by its past. The crisis facing specifically public transportation in South Africa is well known and well documented (Mashiri, Moeketsi \& Baloyi 2013). According to Oxford (2013) 'South Africa is a country in desperate need of a viable and sustainable public transport network'. The legacy of Apartheid is evident in the lack of basic public transport infrastructure if it is considered that approximately 15 million commuters per day (or 60\% - 70\% of the public and workforce) are transported via minibus taxis. Zharare, in Media Update (2011), postulates that the average commuter spends at least 3 hours per day commuting to and from work.

The South African Government has identified various initiatives to elevate the current issues in public transport and intermodal transportation linkage. The various initiatives are captured in the National Transport Master Plan 2050, also known as Natmap 2050. The Natmap 2050 guiding document focuses on the long-term governmental vision of an integrated transport network with various modes of transport complementing each other to create growth within the South African economy.

\section{South African transport industry's regulatory composition}

The South African Constitution governs the role allocation and responsibilities of the various levels of government regarding air, road, traffic management and public sector transportation. Most of the responsibility and implementation of mandates with regards to public transport resides within public entities that are overseen by the Department of Transport (DoT) on a national Governmental level.

The South African DoT's strategic goals are to (South African Government n.d.):

- ensure an efficient and integrated infrastructure network that serves as a catalyst for social and economic development

- ensure a transport sector that is safe and secure

- improve rural access, infrastructure and mobility

- improve public transport systems

- increase the contribution of the transport sector to job creation

- increase the contribution of the transport sector to environmental protection.

On a national level, the 12 entities that report to the Minister of Transport includes Airports Company of South Africa (ACSA), 


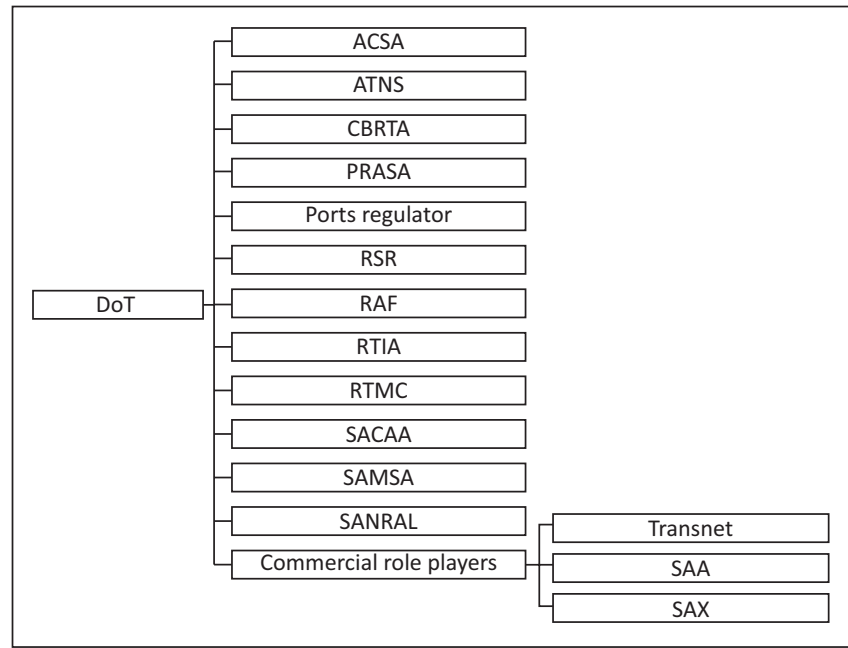

ACSA, Airports Company of South Africa; ATNS, Air Traffic and Navigation Services; CBRTA Cross Border Road Transport Agency; PRASA, Passenger Rail Agency of South Africa; RSR, Ports Regulator, Rail Safety Regulator; RAF, Road Accident Fund; RTIA, Road Traffic Infringement Agency; RTMC, Road Traffic Management Corporation; SACAA, South African Civil Aviation Authority; SAMSA, South African Maritime Safety Authority; SANRAL, South African National Road Agency Limited.

FIGURE 3: National public entities reporting to the Department of Transport.

Air Traffic and Navigation Services (ATNS), Cross Border Road Transport Agency (CBRTA), Passenger Rail Agency of South Africa (Prasa), Ports Regulator, Rail Safety Regulator (RSR), Road Accident Fund (RAF), Road Traffic Infringement Agency (RTIA), Road Traffic Management Corporation (RTMC), South African Civil Aviation Authority (SACAA), South African Maritime Safety Authority (SAMSA) and South African National Road Agency Limited (SANRAL). The following commercial entities also report to the DoT: Transnet, South African Airways (SAA) and South African Express (SAX).

Figure 3 graphically represents the 12 national public entities that reports to the Minister of the Department of Transport.

For the purpose of this study, it should be noted that the Gautrain project is managed at the provincial level by the Gauteng Provincial Government and the Provincial Government reports at the national level to the DoT.

\section{Gautrain project}

The Gauteng Provincial Government in association with local and international stakeholders announced the Gautrain project in 2000. The aim of the project was to build one of the largest and most modern transport networks in Africa. According to Thomas (2011), the Gautrain is the continent's first high-speed rail. Construction on the project started in 2006, with the main stakeholders responsible for the construction being Bombela Consortium, a partnership between Bombardier Transportation, Bouygues Travaux Publics, Murray \& Roberts, the Strategic Partners Group and RATP Development, the J\&J Group and Absa Bank.

The project consisted of two phases, being constructed simultaneously. The first phase of the project, scheduled to take 45 months, was between the O.R. Tambo International Airport, Sandton and Midrand in Gauteng. Phase two of the project, scheduled to be completed within 54 months, focused on the remainder of the network.

Although the project was scheduled to be completed by 2011, the first public passenger trip was made in February 2009 on a 3-km part of the route. The first section of phase one of the project was opened for public use on the 8th of June 2010 with the remainder of the route completed by mid-2012. To date, the entire $80-\mathrm{km}$ route consists of 10 operational stations in Gauteng. These stations include the following:

- Hatfield

- Pretoria

- Centurion

- Midrand

- Marlboro

- Sandton

- Rosebank

- Park Station

- Rhodesfield

- O.R. Tambo International Airport.

According to Venter (2013), the Gautrain Management Agency (GMA) projected that the Gautrain should move 100000 people on the network per day by 2016. Recent statistics indicate that the Gautrain has to date transported 50 million passengers at an average of 1.4 million commuters per month, equating to 45161 commuters per day (Maqutu 2016). If the aforementioned statistic is taken into consideration, the Gautrain is yet to meet its objective of transporting 100000 commuters per day.

Although various factors may be attributed to the aforesaid, Mashiri et al. (2013) is of the opinion that technology adoption coupled with information dissemination to customers is critical for the successful operation of public transport services and in maintaining and stimulating demand for these public transport services.

\section{Mobile applications}

The rapid development of mobile phones and devices over the last decade has resulted in devices and the operating systems of these devices becoming more sophisticated, resulting in an increase in the variety of mobile applications designed for the mobile smart devices. Harris, Brookshire and Chin (2016:441) note that 'as of May 2015, Google's Google Play Market contained 1.5 million apps and Apple's App Market contained 1.4 million'.

Hoehle and Venkatesh (2015:435) state that in most developed countries, smart phone penetration rates have reached more than $100 \%$ per capita, with individuals in general owning more than one device. As smartphone penetration reaches almost $40 \%$ in South Africa (Litha Communications 2016), more and more South African consumers are downloading mobile applications to interact and engage with information on a daily basis. The aforementioned is based on the fact that according to IT News Africa (2015) the South African consumers download most of the applications available in the app stores. Kim, Wang and Malthouse (2015) argue, 'with the explosive growth of mobile 
technologies and app culture, customers' expectations of a useful and enjoyable mobile experience will become the norm'.

Per definition, an application may refer to software applications that have been designed to run on smaller electronic and wireless devices such as smartphones and tablets, the mobile applications may be preloaded on the mobile device or be installed from the respective application stores using the Internet. It should be noted that mobile applications serve to provide users of mobile technology with similar services to those accessed on a personal computer (PC), but with limited functionality (Technopedia n.d.). According to Morrison (2015), there are three types of mobile applications and these types of applications include:

- Native application is an application specifically created for the operating system of the mobile device.

- Web-based is an application that allows the users access to a mobile version of a functioning website.

- Hybrid application may be defined in terms of a combination of the native and hybrid forms of applications.

Recent developments within the mobile application environment allow for the incorporation of the mobile devices features into the application, examples of these application include the incorporation of the camera feature of the phone to capture and share images via application such as WhatsApp.

According to the World Economic Forum (2016), 'many smartphone users have apps for every potential task (e.g. communication, banking, fitness tracking, catching-up on news)'. Because of the diverse nature of the types of applications and their related tasks, Nickerson et al. (2007) proposes taxonomy of mobile applications to assist in the classification thereof. The taxonomy identifies the following categories of mobile applications:

- purchasing location-based contents

- mobile inventory management for a company

- product location and tracking for individuals

- mobile auctions

- mobile games

- mobile financial services

- mobile advertisement

- mobile entertainment services

- mobile personal services

- mobile distance education

- mobile product recommendation systems

- wireless patient monitoring

- mobile telemedicine.

The focus of this study relates to the use of a mobile personal service application, and more specifically the use of the Gautrain Buddy application. Nickerson et al. (2007) define a mobile personal service application

as asynchronous, interactional, transactional (depends on what people are looking for), public, individual, non-location-based (but if the user wants to be alerted every time a potential products or service that comes within a certain distance of the current location, it will become a location-based service), non-identitybased (at least in the beginning due to privacy concerns).

\section{Gautrain Buddy Application}

The Gautrain Buddy application is an independent application created in 2013 by Theo de Bruin, aiming to improve on the Gautrain information dissemination. In 2014, the application won the MTN application of the year award. The Gautrain Buddy application displays the Gautrain timetable data on a mobile phone; it also provides notifications for scheduled trains and a fare calculator. Further features of the application include:

- seamless automatic selection of timetable(s) according to the day of week

- train and bus trips can be saved for easy access

- arrival notifications can be added

- automatic scrolling to the next trip

- the ability to view real time updates.

It important to note that this application is not affiliated to the Gauteng Provincial Government, Gauteng Management Agency, Bombela Concession Company or the Bombela Operating Company.

\section{Methodology and research design}

Mouton (2001:46) is of the opinion that 'all empirical (social) research conforms to a standard logic'. Saunders, Lewis and Thornhill (2012) concur with the aforementioned statement and postulate a high-level logical layout of the research process in the form of a 'research onion'. The research onion provides a framework of various layers of activities and choices that need to be discussed and answered before moving onto the next level or layer of research.

As represented in Figure 4, research philosophy (Saunders et al. 2012) is the first layer or activity to be considered within the research onion. The research philosophy explains the advancement of knowledge and how the research process will contribute towards the body of knowledge within a specific field of study. The importance of the research philosophy should not be underestimated for the theory identified within the research philosophy will govern the design of the research project. Saunders et al. (2012) propose that the main philosophical assumptions include:

- positivism

- realism

- interpretivism

- pragmatism.

Carnaghan (2013) concurs and adds post-positivism, social constructivism, post-modernism, feminist theories and critical theory to the list of basic philosophical assumptions.

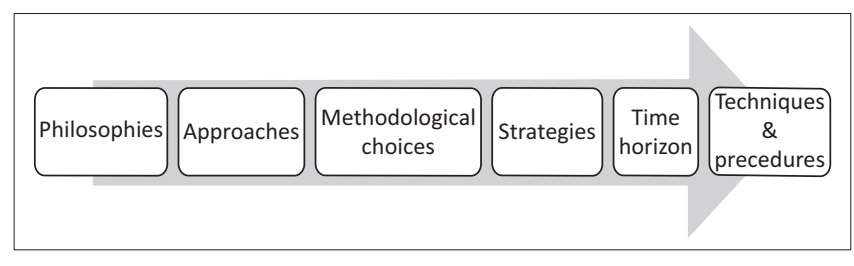

Source: Adapted from: Saunders, M., Lewis, P. \& Thronhill, A., 2012, Research methods for business students, Pearson Education Limited, Oxford.

FIGURE 4: The research onion. 
The design of the research project is portrayed in terms of the research approach that the researcher will follow. Three distinct approaches can be identified, including:

- Deductive approach is one where the researcher starts with a specific theory and designs a research strategy to test the theory.

- Inductive approach is one where the researcher starts by collecting data to explore a phenomenon and generate or build a theory (often in the form of a conceptual framework) based on the data.

- Abductive approach is one where the researcher collects data to explore a phenomenon, identify themes and explain patterns, to generate a new theory or to modify an existing theory, which is subsequently tested through additional data collection.

Following the research approach, the researcher needs to discuss the general plan on how to go about answering the research question(s). The first concept that needs to be addressed is that of quantitative (number-based research) versus qualitative (explanatory-based research) research methodology, thus defining the methodological stance of the study.

The methodological choice will inform and dictate the research strategy. The research strategy focuses on how the researcher will collect data and information to answer the research question(s). Various examples of research strategies may be identified, including but not limited to experiments, surveys, case studies and action research. An important last consideration that the research needs to take into account is the time frame of the study, that is, will it be a snapshot or multiple snapshots over a period of time. A snapshot may also be referred to as a cross-sectional study and multiple snapshots are referred to as a longitudinal study.

For the purpose of this study, the researchers adopted a positivist stance with regards to the philosophical choice of the study. The philosophical stance is based on the fact that the researchers collected data on an observable reality and searched for relationships in the data (Saunders et al. 2012:134). Based on the philosophical stance adopted by the researchers, the research approach is deductive in nature. The TAM theory is used as a departure point in understanding the perceived usefulness and ultimate use of a mobile application in the South African transport industry. The use of a deductive approach also allows for replication of the study. The research design may be defined as the general plan that the researchers will follow to answer the research question. This exploratory research applied a mixed method research design, utilising a survey strategy comprising both closed and open-ended questions in the data collection activity. The study focused on snapshot (i.e. a cross-sectional study) of how commuters perceive the usefulness of a mobile application within the South African transport industry. The total population of commuters utilising the Gautrain on a daily basis is in the range of 45000 . A convenience sample of a hundred Gautrain commuters was selected in an effort to understand the use and perceived usefulness of a mobile application in the South African public transport domain.
The sample was given the questionnaire to complete at the Park Station in Johannesburg.

\section{Limitations of the study}

The study is based on the initial TAM model; it should be noted that the literature review indicated that the initial TAM model does not consider external factors that may influence individuals' beliefs with regards to ease of use and the perceived usefulness of the technology or application under investigation. Only one mobile application (the Gautrain Buddy application) was considered for the study. Due to time constraints, the study only focused on a convenience sample of a hundred commuters of the Gautrain, and it is suggested that future research incorporate a larger sample of commuters.

\section{Results}

Based on descriptive statistics, the results of the questionnaire indicated that $71 \%$ of the respondents utilise the Gautrain Buddy application. Of the $29 \%$ of respondents not using the application, more than half of them indicated that they did not know about the specific application.

The next question posed to the respondents ascertained the frequency of use of the Gautrain. The researchers divided the commuters into either frequent commuters or ad hoc commuters. The frequent commuters had to make use of the Gautrain more than once a week, with the ad hoc users only making use of the Gautrain at least once a month. Out of the population utilising the application, $78 \%$ of the commuters were frequent commuters while $22 \%$ were ad hoc commuters of the Gautrain (Figure 5).

When questioned what type of features are used most frequently, all of the respondents (i.e. regular and ad hoc users of the application) indicated that the ability to track the Gautrain bus service or schedule was the most frequently used feature. In contrast, only $67 \%$ of the application users indicated that they used the application to check the train schedule. The fare calculator was only used by $18 \%$ of the application users; this may be attributed to the fact that there is not a lot of fluctuation in terms of the set route rates. The Gautrain Buddy application notifies its users of any changes in terms of train and bus schedules as well as route fares.

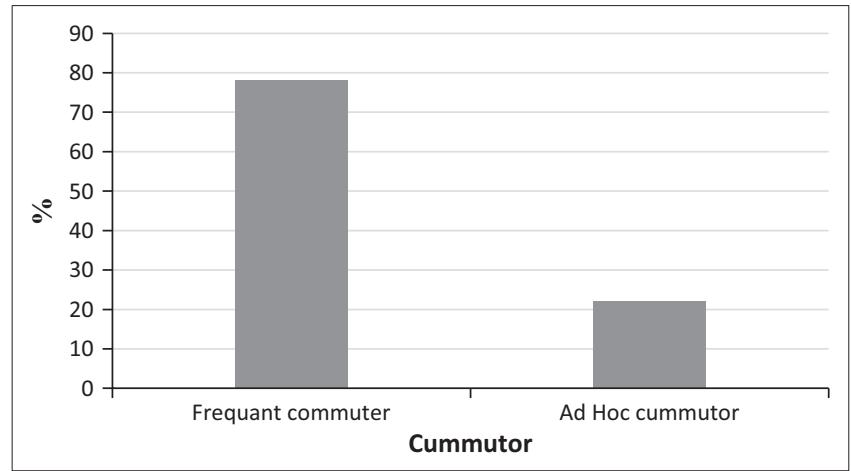

FIGURE 5: Type of commuter. 


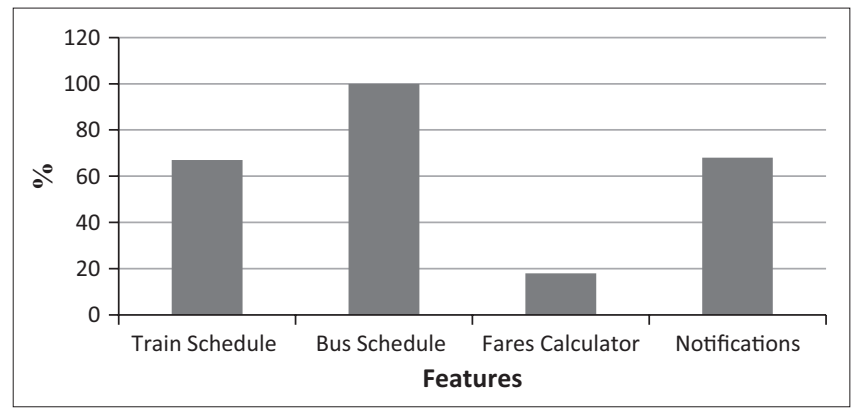

FIGURE 6: Features used.

The notification feature was used by $68 \%$ of the respondents (Figure 6).

Based on the original TAM model as postulated by Davis et al. (1989), perceived usefulness may be defined in terms of the following dimensions:

- allows for work to be completed quickly

- improves activity performance

- increases productivity

- enhances effectiveness

- makes it easier to perform activity

- is useful.

In terms of the perceived usefulness of the Gautrain Buddy application, $69 \%$ of the respondents indicated that the application is useful, with one of the respondents stating that

'The app tell me when the next train is leaving and where I can find the GauBus, this is information that matters to us as commuter because in order to be able to make timely decision, you need information like this as a commuter.' [Male, Student]

It should be noted that $31 \%$ of the users of the Gautrain Buddy application indicated little or no use for the application when commuting via the Gautrain. One of the respondents indicated that:

'it really is not effective for me, the other day the train tracker showed me that the train was still coming and still very far, only to find out that the bus has left 5 minutes ago, the app is not real time, making it not to be effective for me.' [Female, Age 23]

Focusing on the respondents that indicating that the application was useful, the researchers posed a follow-up question relating to the use of the application in planning routes and use app of travel (Figure 7).

It is evident from Figure 8 that $78 \%$ of the respondents indicated that the Gautrain Buddy application was used on a frequent basis to plan for trips and to manage the related times of departure and arrivals.

Figure 9 represents the results of the perceived ease of use of the Gautrain Buddy application. The respondents were presented with the following questions regarding the ease of use of the application:

- Was the application easy to learn?

- Was the application controllable?

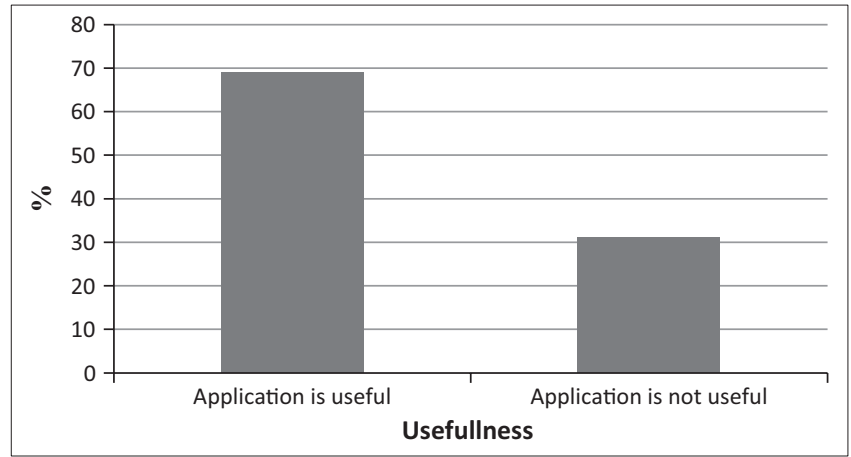

FIGURE 7: Perceived usefulness of the application.

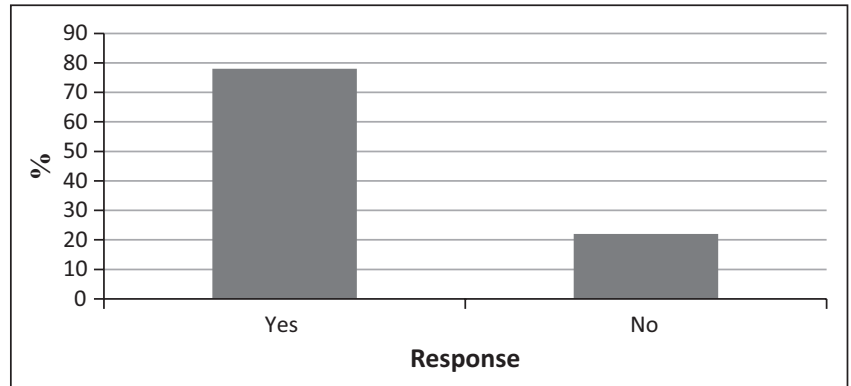

FIGURE 8: Use of the application for planning travel routes and times.

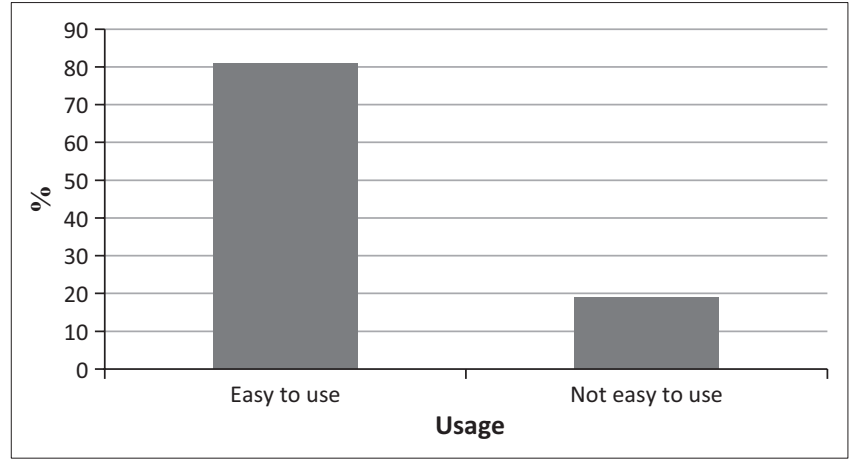

FIGURE 9: Perceived ease of use of the application.

- Was the interaction with the application clear and understandable?

- Was the application is flexible to interact with?

- Was it easy to become skilful?

- Was it easy to use?

Eighty one per cent of the respondents had a positive stance towards the perceived ease of use of the application. It should be noted that $19 \%$ of the respondents indicated that the application based on the questions posed was not easy to use.

Considering the results (the main research question, i.e., 'Does the use of mobile applications assist in information dissemination within the public transport industry in Gauteng, South Africa?'), the commuters opined that the mobile application did not facilitate the dissemination of information to a large extent. Furthermore, the respondents also indicated that the Gautrain Buddy application was easy to use based on the criteria as discussed in the TAM model. The respondents also indicated that the application was useful in assisting with the planning of trips and in the use of the Gautrain. 


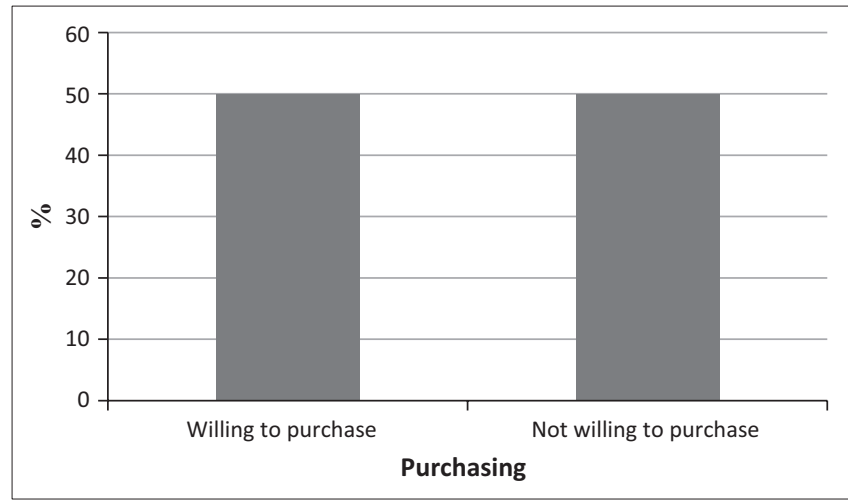

FIGURE 10: Willingness to purchase an application providing functionalities.

An interesting observation was made when the last question was posed to the respondents, that is, 'Are the respondents willing to purchase an application that offers the commuters similar functionalities?, As indicated in Figure 10,50\% of the respondents were willing to purchase the application or an application with similar features, whereas $50 \%$ of the respondents were not willing to purchase the application or an application with similar features.

\section{Conclusion}

Based on the fact that the transport industry may be regarded as early adopters of technology, this study focused on the use the Gautrain Buddy application in the dissemination of information on related Gautrain-specific information. The research findings suggest that commuters utilising the Gautrain Buddy application perceive the application as being useful in the dissemination of information. Furthermore, the research finding also suggests a positive relationship in terms of the perceived ease of use of mobile application in the dissemination of information in the public transport industry.

\section{Acknowledgements Competing interests}

The authors declare that they have no financial or personal relationship(s) that may have inappropriately influenced them in writing this article.

\section{Authors' contributions}

C.J.P.N. was responsible for $80 \%$ and the writing of article and results. H.C. was responsible for the remaining $20 \%$, the initial research and collecting data.

\section{References}

Agherdien, N., 2007, 'A review of theoretical frameworks in Educational Information and Communication Technology Research at leading South African Universities', Masters' dissertation, University of Johannesburg.

Carnaghan, I., 2013, Philosophical assumptions for qualitative research, viewed 30 January 2015, from https://www.carnaghan.com/2013/03/philosophicalassumptions-for-qualitative-research/

Challenger, 2015, Through technology, the industry is changing, viewed 12 January 2015, from https://www.challenger.com/changing-technology-in-trucking/
Cusanelli, M., 2014, Survey: Early tech adopters have competitive advantage, viewed 30 January 2015, from http://thevarguy/com/virtualization-applications-andtechnologies/092214/survey-early-tech-adopters-have-competitive-advantage

Davis, F.D., Bagozzi, R.P. \& Warshaw, P.R., 1989, 'User acceptance of computer technology: A comparison of two theoretical models', Management Science 35(8), 982-1003. https://doi.org/10.1287/mnsc.35.8.982

Fădor, A.G., 2014, 'Innovation and technology acceptance model (TAM): A theoretical approach', Romanian Journal of Marketing 2, 59-65.

Flick, U., 1998, An introduction to qualitative research, Sage, London.

Gorard, S., 2004, 'Sceptical or clerical? Theory as a barrier to the combination of research methods', Journal of Educational Enquiry 5(1), viewed 28 January 2016, from http://www.literacy.unisa.edu.au/jee/Papers/JEEVol5No1/Paper\%201.pdf

Harris, M.A., Brookshire, R. \& Chin, A.G., 2016, 'Identifying factors influencing consumers' intent to install mobile applications', International Journal of Information Management 36, 441-450. https://doi.org/10.1016/j.ijinfomgt.2016.02.004

Harvard Business Review Analytic Services, n.d., The digital dividend-first mover advantage, viewed 28 March 2015, from http://www.verizonenterprise.com/ resources/insights/hbr/

Hoehle, H. \& Venkatesh, V., 2015, 'Mobile application usability: Conceptualization and instrument development', MIS Quarterly 39(2), 435-472.

IT News Africa, 2015, Study reveals African mobile phone usage stats, viewed 02 January 2015, from http://www.itnewsafrica.com/2015/04/study-revealsafrican-mobile-phone-usage-stats/

Kim, S.J., Wang, R.J.H. \& Malthouse, E.C., 2015, 'The effects of adopting and using a brand's mobile application on customers' subsequent purchase behavior', Journal of Interactive Marketing 31, 28-41. https://doi.org/10.1016/j.intmar.2015.05.004

Lala, G., 2014, The emergence and development of the technology acceptance model (TAM), viewed 28 January 2015, from http://0-web.b.ebscohost.com.ujlink.uj.ac.za/

Lee, Y., Kozar, K.A. \& Larsen, K.R., 2003, 'The technology acceptance model: Past, present, and future', Communications of the Association for Information Systems 12(1), 752-780.

Litha Communications, 2016, Technology pushes events into experience, viewed 28 January 2016, from http://www.bizcommunity.com/Article/196/40/139697.html

Mashiri, M.A.M., Moeketsi, P.N. \& Baloyi, V., 2013, Increasing public transport market share in South Africa: The options, viewed 28 January 2016, from http://www. thredbo-conference-series.org/downloads/thredbo6_papers/Thredbo6-theme4Mashiri-Moeketsi-Baloyi.pdf

Maqutu, A., 2016, Popularity of Gautrain likely to result in falling subsidies, viewed 28 February 2016, from http://www.bdlive.co.za/business/transport/2016/01/15/ popularity-of-gautrain-likely-to-result-in-falling-subsidies

Media Update, 2011, ComutaNet's Rejoice Zharare looks at commuters and media consumption, viewed 28 January 2015, from http://www.mediaupdate.co.za/ marketing/40910/comutanets-rejoice-zharare-looks-at-commuters-and-mediaconsumption

Morrison, J., 2015, What is a mobile app?, viewed 28 January 2015, from http://blog. deepbluesky.com/blog/-/what-is-a-mobile-app_161/

Mouton, J., 2001, How to succeed in your master's and doctoral studies: A South African guide and resource book, Van Schaik, Johannesburg.

Nicholas, D., Dobrowolski, T., Withey, R., Russell, C., Huntington, P. \& Williams, P., 2003, 'Digital information consumers, players and purchasers: Information seeking behaviour in the new digital interactive environment', Aslib Proceedings: New Information Perspectives 55(1/2), 23-31. https://doi.org/10.1108/ New Information

Nickerson, R., Varshney, U., Muntermann, J. \& Isaac, H., 2007, Towards a taxonomy of mobile applications, viewed 20 January 2010, from https://courses.cs.washington. edu/courses/csep590b/11wi/readings/taxonomy.pdf

Niemand, C.J.P. \& Chauke, H., 2016, 'An exploratory study of the use of mobile application by public transport commuters in Gauteng', 7th Biennial Conference of the Academy of World Business, Marketing and Management Development, Cracow.

Oxford, T., 2013, The state of SA's public transport, viewed 28 January 2016, from http://mg.co.za/article/2013-10-04-00-the-state-of-sas-public-transport

Pettigrew, K.E. \& McKechnie, L., 2001, 'The use of theory in information science research', Journal of the American Society for Information Science and Technology 52(1), 62-73. https://doi.org/10.1002/1532-2890(2000)52:1<62::AIDASI1061>3.0.CO;2-J

Prensky, M., 2001, Digital native, digital immigrants, viewed 28 January 2016, from http://pre2005.flexiblelearning.net.au/projects/resources/Digital_Natives Digital_Immigrants.pdf

PwC, n.d., Africa gearing up. Future prospects in Africa for the transportation \& logistics industry, viewed 28 January 2016, from https://www.pwc.co.za/en/ assets/pdf/africa-gearing-up.pdf

Radomir, L. \& Nistor, V.C., 2013, 'An application of technology acceptance model to Internet Banking services', International Conference 'Marketing - From information to decision' 6th Edition 2013, viewed 28 January 2016, from http://0 web.b.ebscohost.com.ujlink.uj.ac.za/

Robinson, A., 2015, Mobile technology in transportation management \& the future impact on the supply chain, viewed 28 January 2015, from http://cerasis. com/2015/02/04/mobile-technology-in-transportation-management/

Saunders, M., Lewis, P. \& Thronhill, A., 2012, Research methods for business students, Pearson Education Limited, Oxford. 
Spink, A., 2004, 'Multitasking information behaviour and information task switching: An exploratory study', Journal of Documentation 60(4), 336-351. https://doi. org/10.1108/00220410410548126

South African Government, n.d., Transport, viewed 28 January 2016, from http:// www.gov.za/about-sa/transport

Technopedia, n.d., Mobile applications, viewed 28 January 2016, from https://www. techopedia.com/definition/2953/mobile-application-mobile-app

Thomas, D.P., 2011, The Gautrain project in South Africa: A cautionary tale, viewed 28 January 2016, from http://www.tandfonline.com/doi/abs/10.1080/02589001.20 13.747292?journalCode=cjca20
Venter, I., 2013, Gautrain passenger numbers tick up, but below initial estimates, viewed 28 January 2016, from http://www.engineeringnews.co.za/article/ gautrain-2013-01

Wentzel, J.P., Diatha, K.S. \& Yadavalli, V.S.S., 2013, 'An application of the extended Technology Acceptance Model in understanding technology-enabled financial service adoption in South Africa', Development Southern Africa 30(4-5), 659-673. https://doi.org/10.1080/0376835X.2013.830963

World Economic Forum, 2016, The impact of digital content: Opportunities and risks of creating and sharing information online, viewed 28 January 2015, from http:// www3.weforum.org/docs/GAC16/Social_Media_Impact_Digital.pdf 